\title{
Gender-Age Differences in Transition Rates among Older Adults in Taiwan
}

\author{
Li-Hua Lai \\ Tung-Cheng Chang \\ Kai-Wen Wong \\ Fei-Bi Yang \\ Ching-Hsuan Dai
}

\begin{abstract}
This study investigates the probability in an inhomogeneous multiple state with three states of the Markovian processes in random transitions method and the human mortality database (HMD) among older male and female aged 65 to 89 for 2009 to 2016. This approach reflects transition rate of disability-dead state in the old males high than in the old females which except for 80-84 and 85-89-yearold males groups. Transition rate of health-disability in the old females high than in the old males. For transition rate of health-dead or disability-dead, the female's transition rate is less than that of the male. This empirical findings also provide one of reference of public long-term care programming or long-term care insurance pricing.
\end{abstract}

Keywords — health-dead, health-disability, disability-dead

Li-Hua Lai (Prof.) (Corresponding author)

Department of Risk Management and Insurance/National Kaohsiung First University of Science and Technology

Taiwan

Tung-Cheng Chang (Ph.D. candidate)

Department of Risk Management and Insurance/National Kaohsiung First University of Science and Technology

Taiwan

Kai-Wen Wong (M.B.A. student)

Department of Risk Management and Insurance/National Kaohsiung First University of Science and Technology

Taiwan

\section{Fei-Bi Yang (Master's graduate)}

Department of Risk Management and Insurance/National Kaohsiung First University of Science and Technology

Taiwan

Ching-Hsuan Dai (Master's graduate)

Department of Risk Management and Insurance/National Kaohsiung First University of Science and Technology

Taiwan

\section{Introduction}

The demographic and sociocultural environments can be particularly relevant in shaping risk perceptions and the role of Long-term care (hereinafter LTC) services in society. This issue has obvious relevance for both government- and market-provided economic security systems. Many governments face mounting costs in meeting social program entitlements for long term care expenditure (hereinafter LTCE), health care and benefits (Getzen, T.E., 2000; Grabowski, 2001; Wolff et al., 2008; Kaye et al., 2009; Guo et al., 2014). Although voters often favor continuation of high benefit levels, they resist the tax increases required to maintain them as the population ages. However, standardization of disability measurement is required before disability could replace time-to-death in LTCE projections models (Meijera et al., 2011).

Despite the large literature that explores the trends in functional status and disability patterns among elderly persons, surprisingly few studies have attempted to characterize the set of health and disability transition probabilities with LTCE for care service. The potential impact on the medicare program is large, given how common such limitations are among the elderly (Donald $\mathrm{H}$. Taylor et al., 2006). Understanding health-disability transition probabilities severe enough to trigger long-term care payouts is essential to product budgeting and development (Olivieri and Pitacco, 2001; de Meijer et al., 2011). Based on each transition rate quantifies the feasible flow from one compartment to another. Transition intensity approach refers to the methods of differential equation for calculating transition probabilities from transition intensities over time (Renshaw and Haberman, 1995; Haberman and Pitacco, 1999; Frijters, 2008). A stochastic model to assess mortality and disability risk (Majer et al., 2011) in life annuities with LTC benefits (Levantesi and Menzietti, 2012; Clark et al. 2016) and to focus on transition probability estimates are sensitive to the definition of 'long-term care disability' (Fong et al., 2012).

Three-state Markov process with states of 'the healthdisability', 'the disability-dead' and 'health-dead' has been conducted in the basis for modeling long-term care status transitions (Karlsson et al., 2006). There are fewer studies devoted to the construction of nationally representative estimates of functional status transition rates. In Taiwan, a population-based study, individual aged 65 years or older people is showed to increase from $11 \%$ of the population in 2010 to $20 \%$ by 2025 . In 2011, among all people with disabilities in Taiwan, individual aged 65 years and more is showed to increase from $37.02 \%$ of the population in 2009 to $38.40 \%$ by 2016 .

The goal of this paper is to estimate age-specific healthdisability transition probabilities among older adults aged 65 to 89 for 2009 to 2016. Our analysis adopts a discrete inhomogeneous Markovian process. This paper focuses on an evidence regarding how the health-disability, the disability-dead and health-dead on transition rates vary by age and garden using stochastic and mortality models and these relative LTCE for each transition state. Our results are of interest for several reasons. Firstly, this study provides an evidence regarding how the health-disability, the disabilitydead and health-dead on transition rates vary by age and gender. Secondly, we apply estimated rates of transition and 
Proc. of the Seventh International Conference On Advances in Economics, Management and Social Study - EMS 2017. Copyright (@) Institute of Research Engineers and Doctors. All rights reserved.

ISBN: 978-1-63248-128-3 doi: 10.15224/ 978-1-63248-128-3-38

determine the total public LTCE for each transition state in 2009 and 2016 years, and as one of reference of long-term care programming or LTC insurance pricing. However, if implemented without delay, LTC program will be implemented in 2018 Taiwan.

\section{Model and data}

\section{A. Transition rates model}

It proposed a stochastic environment represented by random transitions in the underlying multiple state model according to Figure 1 (Cairns et al., 2006; Levantesi and Menzietti, 2012). All older people may face health risk. They follow the underlying multiple state model process that involves:

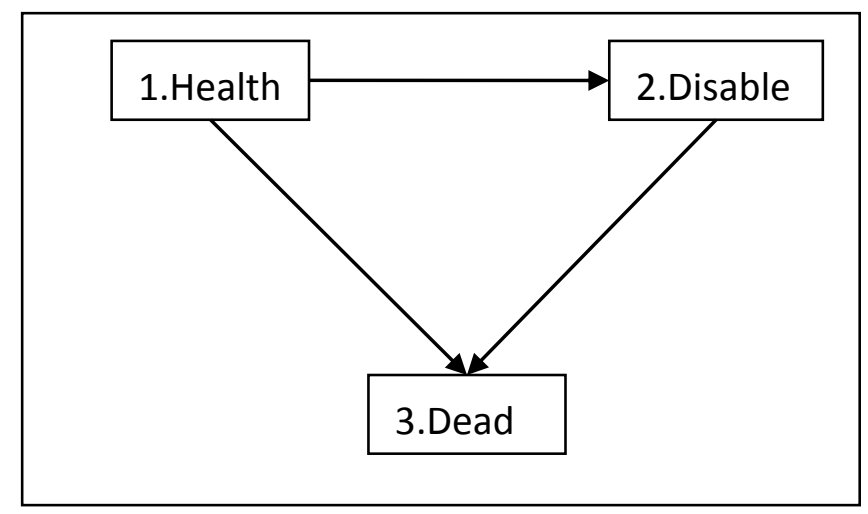

Figure 1. Three-state Markov process

We consider a probability in a stochastic environment represented by random transitions in the underlying multiple state model. We use a discrete and inhomogeneous multiple state model with three states: $1=$ healthy, $2=$ disabled, and $3=$ dead (Haberman and Pitacco, 1999). Let $\{S(\mathrm{t}) ; \mathrm{t}=0,1,2, \ldots\}$ be a Markovian process describing the development of a single policy in discrete time with a finite state space and a set of transitions. Therefore, the random variable $S(\mathrm{t})$ represents the state of the Markov process at time $t$. In order to the usually chronic character of disability for elderly, we disregard the possibility of recovery from the disabled state. This assumption is consistent with the empirical evidence emerging from our dataset, so we assume $S(0)=1{ }_{t} p_{x}^{i j}$ is the probability that the process, being in $i$ state at time $t$, will make a transition to state $j$ in the next stop. In particular, ${ }_{t} p_{x}^{i i}$ is the probability of staying in the same state $i$ at the next time moment. All of them are defined as follows:

$$
\begin{array}{r}
{ }_{t} p_{x}^{i j}=P\{S(\mathrm{t})=\mathrm{j} \mid \mathrm{S}(0)=i\} t \in[0, \mathrm{~T}], \\
i, j \in S, i \neq j \\
{ }_{t} p_{x}^{i i}=P\{S(\mathrm{t})=i \mid \mathrm{S}(0)=i\} t \in[0, \mathrm{~T}], i \in S
\end{array}
$$

For $\mathrm{t}=1,2, \ldots$, we have the Chapman-Kolmogorov equations:

$$
{ }_{t} p_{x}^{11}={ }_{t-1} p_{x}^{11} \bullet p_{x+t-1}^{11}
$$

$$
\begin{gathered}
{ }_{t} p_{x}^{12}={ }_{t-1} p_{x}^{12} \cdot p_{x+t-1}^{22}+{ }_{t-1} p_{x}^{11} \cdot p_{x+t-1}^{12} \\
{ }_{t} p_{x}^{22}={ }_{t-1} p_{x}^{22} \bullet p_{x+t-1}^{22}
\end{gathered}
$$

Remaining probabilities can be calculated as:

$$
{ }_{t} p_{x}^{13}=1-{ }_{t} p_{x}^{11}-p_{x}^{12} \text { and }{ }_{t} p_{x}^{23}=1-{ }_{t} p_{x}^{22}
$$

In this issue, we discuss the one step at time 0 to another step at time 1 . There are equation we are use as the follows:

$$
\begin{gathered}
p^{12}(t+1, x+1)=p^{1}(t, x) \bullet p^{2}(t+1, x+1) \\
p^{13}(t+1, x+1)=p^{1}(t, x) \bullet p^{3}(t+1, x+1) \\
p^{11}(t+1, x+1)=1-p^{12}(t+1, x+1)-p^{13}(t+1, x+1) \\
p^{23}(t+1, x+1)=p^{2}(t, x) \bullet p^{3}(t+1, x+1) \\
p^{22}(t+1, x+1)=1-p^{23}(t+1, x+1)
\end{gathered}
$$

Using equation (6), (7) and (9), we determine the total LTC expenditure, $E_{t}^{i j}$ for each transition state $(i j)$ in one year $t$ to be:

$$
E_{x, t}^{i j}=\sum_{c=1}^{C} \sum_{d=1}^{D} e_{d, c, t} * f\left({ }_{t} p_{x}^{i j}\right)_{d, c, t}
$$

where, $f\left({ }_{t} p_{x}^{i j}\right)_{d, c, t}$ is the frequency after transition estimated from ${ }_{t} p_{x}$ of the elderly persons served, the sum of each services $(d)$ in country $(c)$ for each transition state (ij ) in $x$ aged group in the year $t$, respectively. In this paper, $e_{d, c, t}$ is the unit cost of all items in LTC services for each transition state $(i j)$ in $x$ aged group in the year $t$.

\section{B. Data}

Online reporting of National Long Term Care Program (NLTP) data and Human Mortality Database (HMD) for the health-disability or health-dead transition probabilities and LTC expenditures among older male and female aged 65 to 89 for 2009 to 2016.

\section{Results}

We could calculate the health-disability, health-dead and disability-dead of the Markovian multi-state process in random transitions have an important effect on LTC expenditure using equations (1) - (10) presented earlier. However, both 2009 and 2016 were key years of LTC policy which LTCE for care service was full developed since 2009. The LTC Services Act will be the full implementation of 2016 in Taiwan.

Table 1 presents full estimates for 2009 and 2016 years below and as mentioned above, we can only obtain count data as follows and we also can see that the transition rate (\%) and total LTC of transition in each age group in each state for elderly service in. Within 'the health-disability 
Proc. of the Seventh International Conference On Advances in Economics, Management and Social Study - EMS 2017. Copyright (@) Institute of Research Engineers and Doctors. All rights reserved.

ISBN: 978-1-63248-128-3 doi: 10.15224/ 978-1-63248-128-3-38

state', are generally increasing age leads to increasing levels of transition rate of health-disability state in male and female. Note that the transition rate of health-disability state in the old females high than in the old males and to be subject to larger total LTC of transition in the old females. In 'the disability-dead state', are showed increasing age leads to increasing levels of transition rate of disability-dead state in male and female. However, the transition rate of disability-dead state in the old males high than in the old females and to be subject to larger total LTC of transition in the old males which except for 80-84 and 85-89-year-old males groups. Finally, In 'the health-dead state', also are generally increasing age leads to increasing levels of transition rate of health-dead state in male and female. In particular, have recently witnessed a trend toward largescale building medical health care network, long care communities and take-care themselves projects with associated positive values that loom large as a proportion of the country's total exposure to benefit on the old females better than the old males, and to be subject to reduce total LTC of transition in the old females. These phenomena have established that upon reaching the age of 65 , Taiwanese men and women tend to live for a further 18.15 and 21.7 years respectively. About half of the males will live longer than 80 years, while half of the females will live longer than 85 years. As will be showed in Table 1, within public LTCE, except for the old females less than in the old males on total expenditures of the health-dead state, are generally the old females large than in the old males on total expenditures of the health-disability and disability-dead states.

TABLE I. TRANSITION RATES AND PUBLIC LTCE IN THREE STATES, GENDER AND AGE, 2009-2016 TAIWAN

\begin{tabular}{|c|c|c|c|c|c|c|c|c|}
\hline \multirow[t]{2}{*}{ Year } & \multirow[t]{2}{*}{ Gender } & \multirow[t]{2}{*}{ Transition } & \multicolumn{6}{|c|}{ Age } \\
\hline & & & $\begin{array}{c}65- \\
69\end{array}$ & $\begin{array}{l}70- \\
74\end{array}$ & 75-79 & $80-84$ & $85-89$ & Total \\
\hline \multicolumn{9}{|c|}{ Health-Disability } \\
\hline \multirow[t]{4}{*}{2009} & \multirow[t]{2}{*}{ Male } & \begin{tabular}{|c|} 
Transition Rate \\
$(\%)$
\end{tabular} & 3.03 & 4.65 & 7.07 & 10.62 & 11.25 & \\
\hline & & \begin{tabular}{|c|} 
LTC of \\
Transition \\
(USD million) \\
\end{tabular} & 5.57 & 8.55 & 13.01 & 19.53 & 20.70 & 67.36 \\
\hline & \multirow[t]{2}{*}{ female } & \begin{tabular}{|c|} 
Transition Rate \\
$(\%)$ \\
\end{tabular} & 3.76 & 6.42 & 10.75 & 17.46 & 17.42 & \\
\hline & & \begin{tabular}{|c|} 
LTC on \\
Transition \\
(USD million) \\
\end{tabular} & 6.92 & 11.81 & 19.78 & 32.13 & 32.05 & 102.69 \\
\hline \multirow[t]{4}{*}{2016} & \multirow[t]{2}{*}{ male } & \begin{tabular}{|c|} 
Transition Rate \\
$(\%)$ \\
\end{tabular} & 3.09 & 4.80 & 7.30 & 11.25 & 11.89 & \\
\hline & & \begin{tabular}{|c|} 
LTC on \\
Transition \\
(USD million) \\
\end{tabular} & 12.02 & 18.67 & 28.40 & 43.76 & 46.25 & 149.10 \\
\hline & \multirow[t]{2}{*}{ female } & $\begin{array}{c}\text { Transition Rate } \\
(\%)\end{array}$ & 3.78 & 6.45 & 10.80 & 17.42 & 18.24 & \\
\hline & & \begin{tabular}{|c|} 
LTC on \\
Transition(USD \\
million) \\
\end{tabular} & 0.77 & 1.40 & 3.55 & 12.09 & 11.33 & 220.52 \\
\hline \multicolumn{9}{|c|}{ Disability-Dead } \\
\hline 2009 & male & $\begin{array}{c}\text { Transition Rate } \\
(\%)\end{array}$ & 0.42 & 0.76 & 1.93 & 6.57 & 6.16 & \\
\hline
\end{tabular}

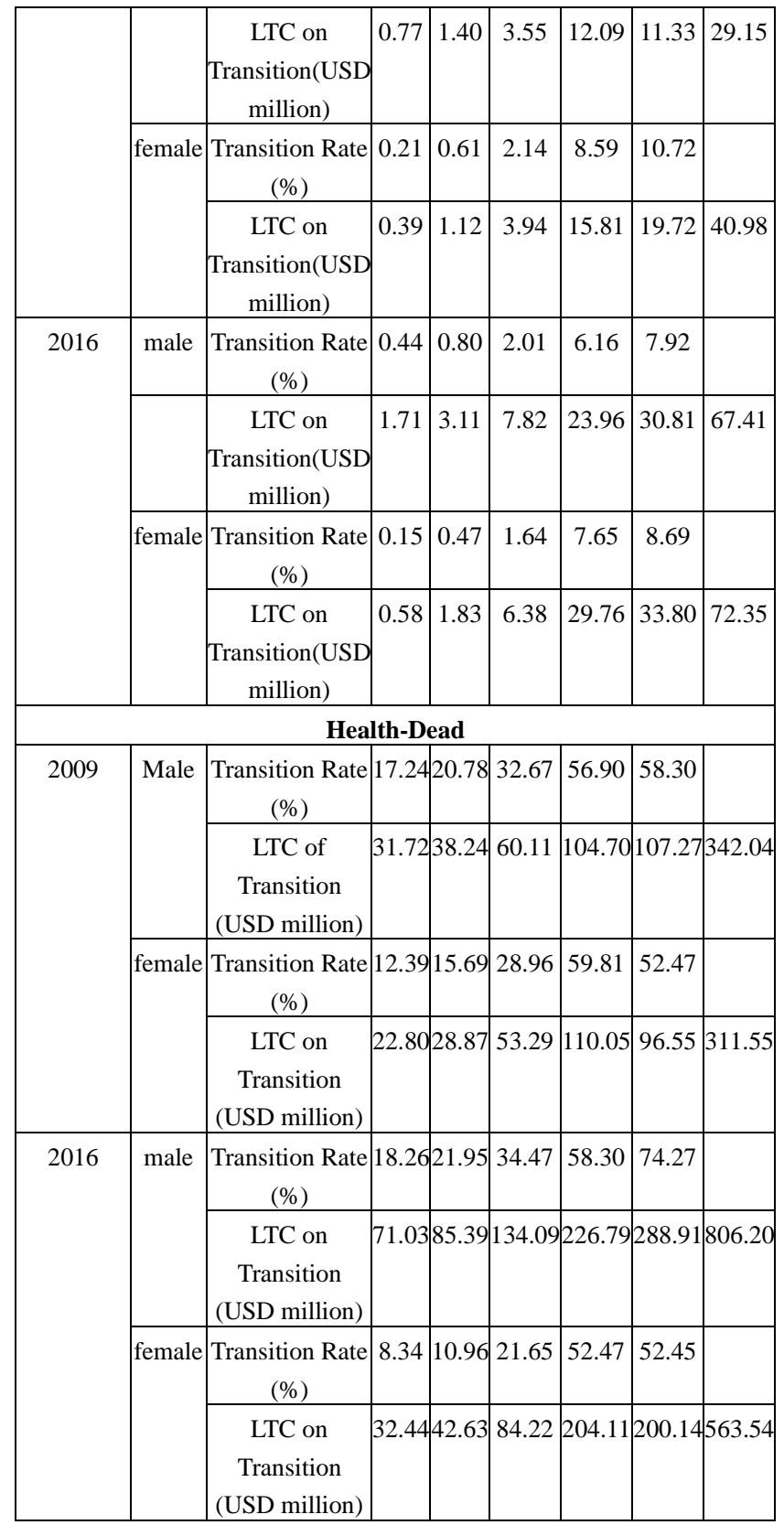

\section{Conclusion and discussion}

Most of developed countries, as the number of elderly people with disabilities or requiring support in their activities of daily living (ADLs) increase, the demand for LTC services has also increased and consequently, the expenditures of the LTC system are growing steadily, threatening the financial sustainability of the system (de Meijer et al., 2011). Standardization of disability measurement is required before disability could replace time-to-death in LTCE projections models (Meijera et al., 2011). Incorporation of proximity to death into health expenditure projection models will prove critical to more accurate estimation of future health expenditure trends, which will better meet the challenge of population ageing (Seshamani and Gray, 2004; Majer et al., 2011). Several studies have shown to varying degrees that excluding TTD results in overestimation of future HCE if future mortality rates are expected to decrease (Stearns and Norton, 2004; Polder et al., 2006; Meijera et al, 2011). These estimation 
Proc. of the Seventh International Conference On Advances in Economics, Management and Social Study - EMS 2017. Copyright (C) Institute of Research Engineers and Doctors. All rights reserved.

ISBN: 978-1-63248-128-3 doi: 10.15224/ 978-1-63248-128-3-38

problems may also show in LTCE and for concern. However, if implemented without delay, LTC program will be implemented in 2018 Taiwan.

This paper assesses health-disability, health-dead or disability-dead of transition rates for elderly individuals within a multi-state model for health policy with long-term care applications for older adults between age 65 to age 89 . We use the Markovian multi-state process in random transitions of the health-disability, health-dead or disabilitydead to estimate the transition probabilities of healthdisability, health-dead or disability-dead in the age-specific. Among all people with disabilities in Taiwan, individual aged 65 years and more is showed to increase from $37.02 \%$ of the population in 2009 to $38.40 \%$ by 2016 .

We find gender difference in incident disability is an important determinant of the higher prevalence of disability generally observed among female. In other words, females not only have a higher probability of being LTC disabled, but also have a higher probability of becoming disabled (Yena et al. 2014). Based on the transition rate of healthdisability, the female's transition rate is higher than that of the male's and indicates that health-disability transition rates are increasing by years. Although the transition rate of health-dead or disability-dead, the male's transition rate is higher than that of the female's. In Taiwan, older women are similarly more likely to live alone than men of the same age and might thus have less access to informal care: older men perhaps still live with a spouse who can act as an informal caregiver, whereas older women are more often widowed (Schwarzkopf et al. 2011; Yena et al. 2014). However, within public LTCE, except for the old females less than in the old males on total expenditures of the health-dead state, are generally the old females large than in the old males on total expenditures of the health-disability and disability-dead states. We know that older people needs for LTC services are usually not satisfied. More well-factors such as lifestyle and access to medical care systems are associated with a decrease in the transition rate of health-dead or disabilitydead of both male and female, and therefore the adverse consequences of transition rate that do occur has decreased - thus leading to lower risk in Taiwan.

Another possible explanation is that upon reaching the age of 65, Taiwanese men and women tend to live for a further 18.15 and 21.7 years respectively. About half of the males will live longer than 80 years, while half of the females will live longer than 85 years, the statistics showed. Compared with data from the US and European nations, according to Ministry of the Interior's statistics report show that the life expectancy for Taiwanese men is closest to their American and German counterparts, but lower than other advanced European nations. The average lifespan for Taiwanese women is three years higher than that of American women, and close to that their Canadian, British, German and French counterparts. Compared with neighboring Asian nations, the life expectancy in Taiwan is lower than in Japan, South Korea and Singapore, but higher than in China, Malaysia and the Philippines.

In summary, this empirical findings also provide a basis for pure premium of long-term care insurance dependent transition rate of the health-disability, health-dead or disability-dead among older adults using the pricing decision scenario analysis in the different market share, and thus fill a gap to the literature of multi-state actuarial models of the health-disability, health-dead or disability-dead for the long-term care insurance and long-term care policy.

\section{References}

[1] Cairns, A.J.G., Blake, D., Dowd. K., 2006. A two-factor model for stochastic mortality with parameter uncertainty: theory and calibration. Journal of Risk and Insurance 73, 687-718.

[2] Clark, D. E., Ostrander, K. R., Cushing B. M., 2016. A multistate model predicting mortality, length of stay, and readmission for surgical patients. Health Services Research 51, 1074-1094.

[3] de Meijer, C., Koopmanschap, M., Uva, T.B., van Doorslaer, E., 2011. Determinants of long-term care spending: age, time to death or disability? Journal of Health Economics 2, 425-438.

[4] Donald H. Taylor, Jr., Hoenig, H. 2006. Access to health care services for the disabled elderly. Health Services Research 41, 743-758.

[5] Fong, J. H., Koh, B. S., Mitchell. O. S., 2012. Functional disabilities and nursing home admittance. Pension Research Council Working Paper 2012-2019.

[6] Frijters, P., Ulker, A., 2008. Robustness in health research: do differences in health measures, techniques, and time frame matter? Journal of Health Economics 27, 1626-1644.

[7] Getzen, T.E., 2000. Health care is an individual necessity and a national luxury: applying multilevel decision models to the analysis of health care expenditures. Journal of Health Economics 19, 259-270.

[8] Grabowski, D.C., 2001. Medicaid reimbursement and the quality of nursing homecare. Journal of Health Economics 20, 549-569.

[9] Guo, J., Konetzka, R. T., Dale. W., 2014. Using time trade-off methods to assess preferences over health care delivery options: a feasibility study. Value in Health: Journal of the International Society for Pharmacoeconomics and Outcomes Research 17, 302-305.

[10] Haberman, S., Pitacco, E., 1999. Actuarial models for disability insurance, Boca Raton: Chapman and Hall / CRC.

[11] Kaye, H. S., LaPlante, M. P., Harrington, C. 2009. Do noninstitutional long-term care services reduce medicaid spending? Health Affairs 28, 262-272.

[12] Karlsson, M., Mayhew, L., Plumb, R., Rickayzen, B., 2006. Future costs for long-term care cost projections for long-term care for older people in the United Kingdom. Health Policy, 75,187-213.

[13] Levantesi, S., Menzietti, M., 2012. Managing longevity and disability risks in life annuities with long term care. Insurance: Mathematics and Economics 50, 391-401

[14] Majer, I.M., Nusselder, W.J., Mackenbach, J.P., Klijs, B., van Baal, P.H.M., 2011. Mortality risk associated with disability: a populationbased record linkage study. American Journal of Public Health 12, 9. 15 .

[15] Meijera, Claudine de., M. Koopmanschapa, T. Bago d' Uva, E. van Doorslaera, 2011. Determinants of long-term care spending: Age, time to death or disability? Journal of Health Economics 30, 425-438.

[16] Olivares-Tirado, P., Tamiya, N., Kashiwagi, M., Kashiwagi, K., 2011. Predictors of the highest long-term care expenditures in Japan. BMC Health Services Research, 17, 103

[17] Olivieri, A., Pitacco, E. 2001. Facing LTC risks, Proceedings of the 32 International ASTIN Colloquium, Washington.

[18] Polder, J.J., Barendregt, J.J., van Oers, H., 2006. Health care costs in the last year of life - the Dutch experience. Social Science and Medicine 63, 1720-1731.

[19] Renshaw, A. E., Haberman, S. 1995. On the graduations associated with a multiple state model for permanent health insurance. Insurance: Mathematics and Economics 17, 1-17.

[20] Schwarzkopf, L., Menn, P., Simone Kunz, S. Holle, R., Lauterberg, J., Marx, P., 2011. Costs of care for dementia patients in community setting: an analysis for mild and moderate disease stage. Value Health $14,827-835$

[21] Seshamani, M., Gray, A., 2004. Ageing and health-care expenditure: the red herring argument revisited. Health Economics 13, 303-314.

[22] Stearns, S.C., Norton, E.C., 2004. Time to include time to death? The future of health care expenditure predictions. Health Economics 13, 315-327.

[23] Wolff, J. L., Kasper, J. D., Shore. A. D., 2008. Long term care preferences among older adults: a moving target? Journal of Aging and Social Policy 20, 182-200. 
Proc. of the Seventh International Conference On Advances in Economics, Management and Social Study - EMS 2017. Copyright $(\odot$ Institute of Research Engineers and Doctors. All rights reserved.

ISBN: 978-1-63248-128-3 doi: 10.15224/ 978-1-63248-128-3-38

[24] Yena, C. F., Chiub, T. Y., Liouc, T. H., Liaoe, H. F. Li, Y. S., Liangg, C. C., Tengi, S. W. (2014) "Does the planned long-term care policy in Taiwan meet the needs of people with disabilities? Health Policy 116, 95-104.

About Author (s):

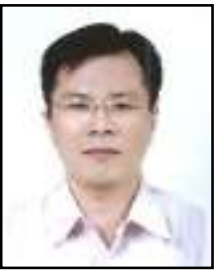

Lihua Lai, is a professor in the Department of Risk Management and Insurance at National Kaohsiung First University of Science and Technology, Taiwan. She has published articles in journals such as Geneva Risk and Insurance Review, Nonlinear Analysis Series B: Real World Applications, Transportation Research Part A: Policy and Practice. Prof. Dr. Lai is a chairman, Southern Region Branch, Risk Management Society of Taiwan. Her research activities include enterprise risk management, property and casualty insurance, actuarial mathematics, insurance financial and economic and agricultural risk assessment.

Tung-Cheng Chang now is a Ph.D candidate of Risk Management and Insurance at National Kaohsiung First University of Science and Technology, Taiwan. His specialization is in the risk management of property and casualty insurance.

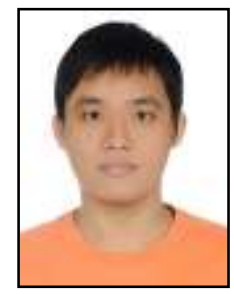

Wong Kai Wen, obtained his master degree of Risk Management and Insurance from National Kaohsiung First University of Science and Technology, Taiwan in 2017. He is interested in financial quantitative analysis and modeling.

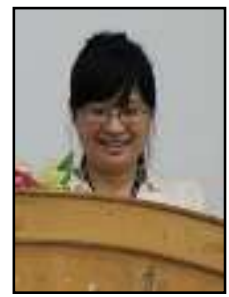

Fei-Bi Yang, received a MBA in the Risk Management and Insurance from National Kaohsiung First University of Science and Technology, Taiwan in 2012. She is an actuary at the Nan Shan Life Insurance Co., Ltd., Taiwan.

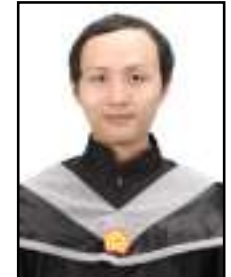

Ching-Hsuan Dai, obtained his master degree of Risk Management and Insurance from National Kaohsiung First University of Science and Technology, Taiwan in 2016. He is an expert in life insurance, personal financial planning and risk management. 